\begin{tabular}{lll}
\hline $\begin{array}{l}\text { Negative cytology with HR HPV } \\
\text { detected }\end{array}$ & $5 / 30$ & Referred for colposcopy \\
$\begin{array}{l}\text { Mild /low grade dyskaryosis } \\
\text { Borderline changes }\end{array}$ & $\begin{array}{l}17 / 30 \\
6 / 30\end{array}$ & $\begin{array}{l}\text { Repeat smear in } 6 \text { months. } \\
\text { 3/6 HR HPV detected were referred for } \\
\text { colposcopy, } \\
3 / 6 \text { HPV not detected had repeat smear in } \\
6 \text { months. }\end{array}$ \\
Moderate dyskaryosis & $1 / 30$ & HR HPV detected, referred for colposcopy \\
Severe dyskaryosis & $1 / 30$ & HR HPV detected, referred for colposcopy \\
\hline
\end{tabular}

Out of the 30 with HR HPV: 5/30 was not on ARV. 25/30 on ARV had HIV VL <50 cpm. Age range from 28-62 years. 22/30 was Black African. 6/30 was white UK.

Conclusions Women with HIV infection who engage in medical care are usually on antiretroviral therapy and are virologically suppressed. The patients with HR HPV were followed up with colposcopy and continue to have annual smears. Patients with negative smear results who are HR HPV negative can be screened as per the normal population.c

\section{P237 HEPATITIS C AMONG MEN WHO HAVE SEX WITH MEN IN GREATER MANCHESTER - THE BASELINE SURVEY}

${ }^{1}$ Georgina Ireland*, ${ }^{2}$ Chris Ward, ${ }^{3}$ Sameena Ahmad, ${ }^{4}$ Ben Goorney, ${ }^{5}$ Steve Higgins, ${ }^{4}$ Catherine Stewart, ' Sam Lattimore, ${ }^{2}$ Vincent Lee. ${ }^{1}$ Public Health England, London, UK; ${ }^{2}$ Central Manchester University Hospitals, Greater Manchester, UK; ${ }^{3}$ University Hospital of South Manchester, Greater Manchester, UK; ${ }^{4}$ Salford Royal NHS Foundation Trust, Greater Manchester, UK; ${ }^{5}$ Pennine Acute Hospitals NHS Trust, Greater Manchester, UK

\subsection{6/sextrans-2015-052126.279}

Background/introduction The number of HIV affected men who have sex with men (MSM) co-infected with hepatitis C (HCV) continues to rise, driven by high risk sexual practice.

Aim(s)/objectives To determine HCV burden and associated risk behaviours among MSM in Greater Manchester.

Methods Between April and October 2014, all MSM attending four GUM clinics were asked to complete a risk assessment questionnaire and HCV screening was offered.

Results There were significant differences in risk behaviour between HIV positive and HIV negative MSM ( $p<0.05)$. Certain risk behaviours were strongly associated with HCV acquisition including: unprotected anal sex, sex with known HCV partners, fisting, group sex, 'slamming' and recreational drug use $(\mathrm{p}<0.002)$.

Discussion/conclusion Our study shows HIV positive MSM have significantly different sexual behaviour which may explain the higher HCV burden. However, HCV was found in HIV negative MSM engaging in high risk sexual practices. All MSM attending sexual health clinics must have a risk assessment and HCV screening should be offered based on the risk. Further studies are warranted to look at the difference in HCV transmission according to the HIV status.

\section{P238 HEPATITIS C TESTING IN MSM - ARE WE ASKING THE RIGHT QUESTIONS?}

Brenton Wait, Rachel Coyle*, lain Reeves, Tristan Barber. Homerton University Hospital, London, UK

\section{$10.1136 /$ sextrans-2015-052126.280}

Background Concern regarding high rates of hepatitis C infection in sub-groups of MSM may warrant targeted testing.
Aim We examine whether we routinely collect the necessary information from MSM to identify those at risk and target hepatitis $\mathrm{C}$ testing, and assess whether our concerns about emerging risk factors for hepatitis $\mathrm{C}$ are implicated in new diagnoses in our cohort.

Methods Notes audit of all MSM GUM attendances during November 2013 assessed documentation of fisting, rectal bleeding with sex, group sex, and drug use, as well as hepatitis testing. Notes of all patients coded for hepatitis $\mathrm{C}$ infection during 2011-2013 were examined to assess risk factors for hepatitis C infection.

Results 147 MSM attendances were reviewed. The proportion of men asked about specific risk factors was: drug use (18\%), rectal bleeding (1\%), group sex (1\%), fisting (1\%). 8\% MSM had hepatitis $\mathrm{C}$ screens, none with traditional risk factors. Over 3 years, 46 patients were coded for hepatitis C. $34 \%$ of these were new infections. $33 \%$ were HIV positive, $48 \%$ had injected drugs (41\% no documentation), $22 \%$ had hepatitis C positive partners, $11 \%$ were sex workers.

Discussion/conclusion Drug use and high risk sexual practices were not always fully recorded in our sample. Testing rates were low and did not seem to relate to identifiable risks. We identified few cases of new infection, largely limited to patients with traditional risk factors. It is not clear if better recording of risk factors would lead to increased Hepatitis $\mathrm{C}$ testing or diagnosis.

\section{Category: Women and children}

\section{P239 DOES SERVICE INTEGRATION IMPROVE THE SEXUAL AND REPRODUCTIVE HEALTHCARE OF HIV POSITIVE WOMEN?}

Sally Wielding*. Chalmers Centre, NHS Lothian, Edinburgh, UK

\section{$10.1136 /$ sextrans-2015-052126.281}

Background NHS Lothian Genitourinary Medicine (GUM) and Sexual and Reproductive Healthcare (SRH) services integrated in June 2011. Contraceptive use, pregnancies and uptake of annual cervical cytology were audited in a cohort of HIV positive women pre- and post-integration of services.

Aims To assess whether the SRH of HIV positive women has improved after integration of services, and to guide further service improvements.

Methods Case notes and electronic data recording system entries were interrogated for the 5 years preceding integration of services and the 3 years following integration.

Results Contraception: Pre-integration $24.9 \%$ of 70 women with contraceptive needs were on effective prescriptions. Postintegration this proportion rose to $39.3 \%$ of 74 women.

Pregnancies: In the 5 years pre-integration 32 women had 42 pregnancies. $47.6 \%$ of these pregnancies were unplanned (UP). In the 3 years post-integration 13 women had a total of 18 pregnancies, $50 \%$ were UP pregnancies.

Cervical cytology: Pre-integration $47.3 \%$ of those eligible had a cervical cytology result documented within the last year, which improved to $74.6 \%$.

Conclusion Contraceptive provision improved after service integration although there remained fewer than $40 \%$ of women using a suitable method. Despite this improvement, UP pregnancy rates did not fall significantly. In a cohort of women attending an integrated service regularly, who are known to have an infection which can be vertically transmitted, it is 
disappointing that rates are comparable to those seen in the general population. The proportion of women who had cervical cytology in the last year has improved from $47.3 \%$ to $74.6 \%$.

\section{P240 EVALUATING CURRENT CONTRACEPTIVE PRACTICE IN WOMEN ATTENDING TERMINATION OF PREGNANCY SERVICES IN GLASGOW}

Rebecca Orr*, Soosan Romel. Sandyford Sexual Health Services, NHS Greater Glasgow and Clyde, Glasgow, UK

\subsection{6/sextrans-2015-052126.282}

Background/introduction Despite free contraception in Scotland, over 12,000 terminations of pregnancy (TOP) are carried out annually at great financial cost.

Aim(s)/objectives To quantify methods of contraception in women presenting with unintended pregnancy at a large urban integrated sexual health unit, to identify reasons for failure.

Methods A retrospective case note review of a random sample of 100 women attending termination referral services between October 2013-March 2014.

Results Of attendees, mean age was 26 years. 38\% had used male condoms. 35\% "no contraception". 25\% Oral contraceptive pill. $24 \%$ of condom users and $43 \%$ of COCP reported imperfect use. Additionally, 9\% fell pregnant despite reported use of emergency contraception. $45 \%$ had undergone at least one therapeutic termination previously, of these: $22 \%$ reporting no use of contraception at time of conception. $4 \%$ no contraception ever. $44 \%$ of repeat attenders and $28 \%$ of whole sample reported using LARC methods in the past. $63 \%$ of women stated intention to undertake a LARC method post-procedure, however it is not clear if these were implemented.

Discussion/conclusion Large numbers of repeat TOPs suggests problems with uptake of reliable contraception post-procedure. Counselling at initial consultation - especially for repeat attendees; specific post-termination clinics and support; interventions and education targeted at high risk groups; and advocated use of LARC should reduce repeat procedures. LARC methods of contraception should continue to be encouraged in all females for primary prevention given their extreme effectiveness. Future studies of the actual uptake versus stated intention to use LARC may be insightful.

\section{P241 CONTRACEPTION AND CONDOM USE IN HIV POSITIVE WOMEN}

Michelle Olver*, Carys Knapper. Anuerin Bevan University Health Board, South Wales, UK

\subsection{6/sextrans-2015-052126.283}

Background/introduction The British Human Immunodeficiency Virus Association has published standards for the care of people living with HIV. Condom use is important in preventing transmission of HIV. Preconception care and contraceptive provision allow HIV positive women to plan pregnancy and reduce the risk of vertical transmission.

Aim(s)/objectives To ascertain whether HIV positive women in our service were using effective contraception to prevent pregnancy as well as consistent condom use.

Methods The notes of 61 female patients attending for regular HIV management within our health board were identified and reviewed. The data collected included documented condom use, contraceptive use and whether the method interacted with their treatment.

Results $57 \%$ of women were documented as using contraception, the intrauterine system being the most widely used. $13 \%$ did not need contraception due to the menopause or hysterectomy whilst $11 \%$ were documented as not currently sexually active. 12 women used condoms alone as contraception. All women on antiretroviral treatment were using appropriate forms of contraception. 21 women did not have documentation of condom use although 9 of those women were recorded as not having a partner.

Discussion/conclusion This audit has highlighted that our service requires better documentation of condom usage. Assumptions should not be made that people without partners are not sexually active. Contraception uptake was well documented with appropriate methods used whether on treatment or not. Due to the high failure rate of condoms, emphasis should be made on using them in conjunction with other forms of contraception.

\section{P242 STILL CHILDREN}

Miranda King, Sara Scofield, Cecilia Priestley*. Dorset County Hospital NHS Foundation Trust, Weymouth, UK

\subsection{6/sextrans-2015-052126.284}

Background/introduction Our GUM clinic holds an integrated young person's clinic (YPC). We have used a proforma for under 16s. In 2014 a national proforma for identifying risk of child exploitation, "Spotting the Signs" was published. We decided to expand the use of the proforma to $<18$ s.

Aim(s)/objectives To assess whether expanding the use of the young person's (YP) proforma would identify risk factors and vulnerabilities in 16-17 year olds that may have otherwise been missed.

Methods Casenote review of 50 consecutive YP aged 16-17 attending a YPC.

Results 45(90\%) were female. YP were at high risk of sexually transmitted infection (STI)-9(18\%) past history of STI, 15 $(30 \%)$ last sex with a casual partner, $15(30 \%)>1$ partner in last 3 months, $38(76 \%)$ no or inconsistent use of condoms. 11/37(30\%) screened were diagnosed with an STI (chlamydia 5, PID 4, warts 1, herpes 1). All reported that they felt able to say "no" if they did not want sex, including one who attended following sexual assault and 5 with a history of unconsensual sex. Other than those, no cases of sexual exploitation were identified; however risks/vulnerabilities were identified in many-19(38\%) mental health problems, 21(42\%) self-harm, 41 $(82 \%)$ regular alcohol and $8(16 \%)$ drug use, 12(24\%) low selfesteem. $12(24 \%)$ had had a previous attendance when the proforma was not used.

Discussion/conclusion Expanding the YP proforma to $<18$ s resulted in identifying a significant number of vulnerabilities and risk factors (mainly self-harm and low-self-esteem) for sexual exploitation and STIs that might otherwise have been missed.

\section{P243 "IN AND OUT" - MEASURING OUTCOMES FOR PREGNANCY PREVENTION IN FEMALES ATTENDING SEXUAL HEALTH CLINICS}

Joanna Nelson, Miranda King, Sara Scofield, Karen Kirkham, Cecilia Priestley*. Dorset County Hospitals NHS Foundation Trust, Weymouth, UK

10.1136/sextrans-2015-052126.285 